\title{
Como prescrever exercício em contexto laboral?
}

\section{TIPO DE ARTIGO: Artigo de opinião}

AUTORES: SANTOS M.(1), ALMEIDA A.(2)

As patologias associados a um estilo de vida menos correto são cada vez mais prevalentes na nossa população; parte delas conseguem inclusive associar-se, constituindo entidades de gravidade superior (como é o caso da Síndrome Metabólica). Contudo, ainda assim, a taxa de sedentarismo na população geral é elevadíssima e a generalidade dos profissionais de saúde (além de também não praticar exercício), não está disponível para o prescrever, pelos mais variados motivos.

A equipa de Saúde Ocupacional/ Medicina Curativa pode exercer um papel importante na educação e promoção para a saúde dos trabalhadores e seus familiares, nomeadamente alertando para os riscos do sedentarismo e proporcionando sugestões concretas para o início ou intensificação da atividade física. Um trabalhador mais saudável está mais motivado para colaborar com os objetivos da empresa e torna-se mais produtivo, não só pela maior capacidade direta de trabalho, mas também pelo menor número/ gravidade de acidentes de trabalho e doenças profissionais, bem como pelo menor número e duração de ausências por certificados de incapacidade médica e menor número de reformas antecipadas.

\section{Distinção entre atividade física, exercício e desporto}

Define-se "atividade física" como sendo qualquer movimento produzido através dos músculos esqueléticos, do qual resulta dispêndio de energia; ou seja, estão aqui incluídas todas as tarefas realizadas (domésticas, profissionais, desportivas ou de lazer) ${ }^{1-9}$. Por sua vez, existe "exercício" quando esse movimento é planeado/ organizado com o objetivo concreto de melhorar alguns parâmetros pré-estipulados ${ }^{1,2,4,5,8-10}$. Quando se acrescenta a dimensão da competição (profissional ou não), atinge-se o patamar designado por "desporto"1; aqui o objetivo principal é o maior rendimento atlético e não propriamente melhorar o estado de saúde; aliás, até são por vezes usados métodos com resultados medicamente prejudiciais.

\section{Intensidade do exercício}

Existem várias formas de aferir a intensidade do exercício. De forma muito simplista poderse-á considerar que a atividade física suave carateriza-se por não alterar a frequência respiratória; no nível moderado e intenso tal já ocorre, surgindo também alterações da temperatura corporal e sudorese ${ }^{1}$. 
O gasto calórico pode ser quantificado através da calorimetria direta ou indireta, bem como pela água duplamente marcada; contudo, estes métodos são dispendiosos, morosos, exigentes tecnicamente e alteram o próprio exercício ${ }^{11}$.

O sistema METs (equivalentes metabólicos) estima o custo de determinada atividade física em comparação com o gasto basal do organismo. Segundo este método uma atividade tem intensidade suave se gastar até 3 MET, moderada se de 4 a 6 e vigorosa se superior a este último valor ${ }^{3}$.

Outro método utilizado para estimar a intensidade do exercício é através da frequência cardíaca máxima, obtida pela subtração da idade a 220 e trabalhando posteriormente percentualmente, em relação a esse valor ${ }^{3,11-13}$. O método da frequência cardíaca máxima apresenta boa correlação com as técnicas mais complexas, uma vez que esta se relaciona diretamente com o consumo de oxigénio ${ }^{11}$. Outros autores, por sua vez, defendem o uso das fórmulas aproximadas, indicadas no Quadro 1. Contudo, devemos não esquecer que a frequência cardíaca também é influenciada pela temperatura, stress, humidade, cafeína, fármacos, desidratação, posição do corpo, tamanho da massa muscular envolvida do movimento, fadiga e morbilidades prévias $^{13}$.

A escala de Borg, por sua vez, também se correlaciona bem com o consumo máximo de oxigénio ${ }^{13}$.

No Quadro 2 constatam-se algumas comparações entre os diversos métodos para estimar a intensidade do exercício ${ }^{13}$. Contudo, o método mais acessível e prático é o "teste da conversa"; este baseia-se no fato de considerar que atividades suaves permitem que o indivíduo converse com facilidade; nas de intensidade moderada já o faz com dificuldade e nas de intensidade vigorosa dificilmente articula várias palavras seguidas sem ficar muito ofegante ${ }^{14}$.

\section{Adesão ao programa de exercício}

$\mathrm{Na}$ maioria dos países desenvolvidos a generalidade da população é inativa ou pouco ativa. A decisão de praticar ou não exercício é cognitiva, resultando do balanço das vantagens/ desvantagens, apoios/ condições e experiências prévias. Aliás, alguns autores concluíram que o prazer e a diversão constituíam motivações mais fortes do que os benefícios diretos em algumas patologias ${ }^{15,16}$. Para além disso, a motivação para iniciar um programa de exercício pode ser diferente da que existirá para o manter. Globalmente, os indivíduos iniciam e/ ou mantêm o exercício quando consideram que os benefícios superam os custos (esforço físico, dinheiro, tempo). O fato de percecionarem que estão ou não a atingir os seus objetivos, também modela a motivação e adesão ${ }^{16}$; ou seja, esta diminui drasticamente se as expetativas não forem realistas ${ }^{17,18}$. Ainda assim, para a generalidade da população, é muito mais fácil conseguir que haja aumento da atividade física nas tarefas já existentes do que iniciar a prática de exercício. ${ }^{19} \mathrm{Em}$ alguns contextos, ambicionar determinado aspeto físico diferente do atual pode constituir a motivação mais intensa para praticar exercício ${ }^{16}$.

Prochasca e Diclemente elaboraram uma teoria relativa a estadios para atingir mudanças comportamentais, que inclui as fases de pré-contemplação, contemplação, preparação, ação e manutenção; sendo a prescrição de exercício útil apenas a partir da terceira etapa. 
A noção de autoeficácia, de certa forma, relaciona-se com as fases atrás mencionadas, ou seja, o indivíduo não só deve querer, como também deve acreditar que conseguirá alterar o comportamento. Contudo, indivíduos demasiado confiantes também podem criar expetativas demasiado otimistas ${ }^{18}$.

Apesar de 80 a $90 \%$ dos indivíduos que iniciam a prática de exercício afirmarem que se sentem melhor, ainda assim, até $87 \%$ destes desiste nos meses seguintes ${ }^{15}$, mais frequentemente em indivíduos com menor escolaridade ${ }^{16}$.

Está também descrito que o uso de monitores da frequência cardíaca ${ }^{17}$ ou podómetros $7,13,17,20-22$ (contadores de passos) aumentam a adesão; bem como as atividades de grupo (devido à maior interação social e apoio) ${ }^{17,19,20}$, quer presencialmente, quer através de contatos telefónicos dos colegas de treino e dos profissionais de saúde que orientam o projeto. Contudo, outros autores também defendem que, com algumas personalidades, o indivíduo pode se sentir "assediado" com esta proximidade pós-treino, optando por se afastar ${ }^{17}$.

Menos de 5000 passos por dia dão ao indivíduo o estatuto de sedentário, até 7.500 será pouco ativo, até 10.000 ativo medianamente, até 12.500 mais ativo e a partir desse valor é considerado muito ativo; constitui por isso uma mudança razoável aumentar 3000 a 4000 passos por dia, para a generalidade dos indivíduos. Apesar do uso de podómetros ser muito simples e económico, estes não podem ser utilizados em todas as modalidades (por exemplo, aquáticas, na musculação ou ciclismo), nem estes conseguem avaliar a intensidade do movimento, apenas a sua ocorrência. $O$ uso de acelerómetros (quantificadores da frequência e intensidade do movimento) culmina essas falhas mas, pela complexidade e custo, fica geralmente restrito à investigação ${ }^{13}$.

Nos projetos supervisionados por profissionais de saúde, acredita-se que existirá mais sucesso se os seus responsáveis não se comportarem como peritos autoritários no tema, mas sim como facilitadores técnicos para executar as soluções encontradas em conjunto com os participantes ${ }^{17}$. Para além disso, optar por uma modalidade já conhecida do indivíduo e/ ou que lhe agrade, aumenta obviamente a adesão ${ }^{19}$.

Quanto à intensidade do exercício, a adesão é mais elevada para atividades menos vigorosas; aliás, considera-se que tal associação se define graficamente em "U", ou seja, intensidades muito baixas ou muito elevadas são menos apreciadas. Contudo, existem obviamente exceções: alguns indivíduos se praticarem exercício com uma intensidade elevada vão aumentar a sua autoestima ${ }^{15}$; quando a intensidade é imposta também há menor probabilidade de manter a adesão ${ }^{25}$; aumentando a autonomia, diminui-se a ansiedade e aumenta-se a motivação.

Não existe uma estratégia ideal para motivar todos os indivíduos; ainda assim existem alguns pontos recomendados por alguns autores; a prescrição por escrito (em vez de só oralmente) é mais eficaz ${ }^{20}$.

\section{Barreiras alegadas para o exercício}


Algumas das barreiras identificadas para a prática do exercício (sobretudo em mulheres) foram a dificuldade em coordenar as diversas exigências profissionais, domésticas, familiares e escolares; bem como a ausência da perceção de ter tempo de lazer, com consequentes fadigas física e mental e necessidade de repousar. Para além disso, como não percebem (genericamente) a importância do exercício, consideram que tal constitui um luxo ao qual não podem ter acesso, face a outras prioridades subjetivas. Para além disso, a obesidade dificulta e cria desprazer no movimento (mesmo que pouco intenso); a patologia músculo-esquelética é também aqui mais frequente e grave. Em áreas geográficas isoladas ou violentas, muitos indivíduos também consideram perigoso andar sozinho na rua e/ ou sentem que não têm nas proximidades infraestruturas adequadas para praticar exercício ${ }^{23,24}$.

Como principais fontes de desprazer são citadas a dispneia (dificuldade respiratória), dor músculo-esquelética e alterações da temperatura/sudorese; existem mesmo alguns indivíduos que têm medo que tal possa levar a consequências médicas graves ${ }^{15}$ e, obviamente, atividades que causem desprazer apresentam menor probabilidade de repetição ${ }^{25}$. Por vezes, esse desconforto pode ser atenuado através da música ou televisão, durante o treino ${ }^{26}$.

Outra barreira descrita é a falta de conhecimentos técnicos específicos para a prática de exercício ${ }^{23,24}$ ou até (de forma muito mais frequente) uma suposta falta de tempo 26 .

Noutros casos percebe-se que o indivíduo vê o exercício como algo que pode perfeitamente ser substituído por medicação (no contexto de prevenir ou atenuar algumas patologias), tem medo de eventuais lesões, receia aumentar de peso e/ ou não tolera o desconforto/ dor ou aumento das frequências cardíaca e/ ou respiratória ${ }^{24}$.

Por sua vez, da parte dos próprios profissionais de saúde, muitos também referem falta de tempo na consulta para abordarem o exercício, pouca formação/ treino na prescrição, desmotivação pela pouca adesão e falta de apoios estruturais. Seria então muito relevante desenvolver o tema na formação de base da generalidade dos profissionais de saúde ${ }^{27}$. A maioria, quando prescreve exercício, mais frequentemente dá indicações orais muito genéricas, versus escritas. Num estudo canadiano, $41 \%$ destes afirmou não prescrever e $85 \%$ considerava não ter formação para o fazer; profissionais de saúde mais ativos, ainda assim, valorizavam mais o tema e prescrevem mais frequentemente ${ }^{28}$.

\section{Tipos de exercício}

Existem três grandes tipos de exercício: aeróbico, com resistência/ carga e de flexibilidade/ equilíbrio $^{3}$. De forma muito simplista o primeiro carateriza-se pelo uso dos grandes músculos e geralmente por períodos prolongados ${ }^{29,30}$, surgindo aumento da frequência cardíaca $^{30}$; como exemplos podem ser citados a caminhada, corrida, natação, ciclismo e dança ${ }^{3,30}$. O segundo tipo de exercício tem o objetivo de fortalecer a massa muscular ${ }^{3}$, geralmente através da manipulação de cargas. Os exercícios de flexibilidade aumentam a amplitude e capacidade de mobilização, ao menor risco de lesão; podendo subdividir-se em dinâmicos ou estáticos ${ }^{30}$. 
O treino com resistência utiliza a sobrecarga dos músculos esqueléticos, de modo a estes ficarem mais robustos, funcionais e hipertrofiados ${ }^{31}$. Essa carga é geralmente quantificada por comparação percentual com a carga máxima que o indivíduo consegue mobilizar pelo menos uma vez, para determinado exercício; além deste valor define-se ainda o número de séries a executar e o número de repetições em cada série; outras variáveis são os intervalos de tempo entre as séries e utilizado para cada flexão/ extensão, bem como a ordem dos exercícios ${ }^{31-33}$. Quanto maior o repouso, maior a capacidade de realizar mais repetições na série seguinte; este poderá ser de 3 a 5 minutos ${ }^{32}$ para permitir o reabastecimento adequado da fosfocreatinina. Caso contrário, passa-se a utilizar o sistema glicolítico, que implica acumulação de iões $\mathrm{H}^{+}$e alterações nas concentrações do sódio, potássio, cálcio, magnésio e cloro, diminuindo-se o pH intracelular que, por sua vez, diminui a força isométrica e a velocidade máxima de contração. Contudo, também está descrito que períodos de repouso menores que um minuto, devido à estimulação da hormona do crescimento, levam a uma maior hipertrofia muscular. Para além disso, quanto maior a carga e tempo de repouso, maior o número de unidades motoras recrutadas ${ }^{32,33}$. Outros defendem ainda que quando se valoriza a hipertrofia, devem-se preferir repousos menores (um a dois minutos) e cargas mais elevadas, contudo, se se pretende aumentar a resistência muscular, deve-se diminuir ainda mais o intervalo entre as séries (30 a 60 segundos) $)^{33}$.

Generalizando, a maioria dos programas utiliza três séries, com cerca de $80 \%$ da capacidade máxima, com 5 a 9 repetições (se se valorizar o aumento da força) ou 9 a 19 repetições (se se pretende desenvolver a resistência muscular). Quanto à ordem de execução, geralmente fazem-se primeiro os exercícios que envolvam massas musculares maiores. Quanto à velocidade, atletas menos experientes devem fazer o treino mais devagar, para diminuir o risco de lesão ${ }^{31}$. Quanto ao número de treinos por semana, a generalidade dos autores recomenda dois a três, para que haja recuperação muscular ${ }^{31,33}$, sobretudo na fase inicial (pois alguns profissionais treinam sete dias por semana, mas alternando os músculos trabalhados); para além disso, quanto menor o número de dias, maior a adesão, generalizando. ${ }^{33}$ Quanto à intensidade, a carga considera-se elevada se superior a $85 \%$ da carga máxima e moderada se na ordem dos $50 \%$; esta pode ser proveniente do próprio peso do indivíduo, halteres, máquinas de peso ou bandas elásticas ${ }^{30}$. Contudo, a evidência científica clara e irrefutável para defender um esquema não existe ${ }^{31}$.

O aumento do volume muscular ocorre quer pelo aumento do número de fibras, atrofia e/ ou aumento da deposição do tecido entre elas ${ }^{33}$.

Indivíduos mais musculados gastam mais calorias em repouso; para além disso, após uma sessão de exercício, é gasto o dobro das calorias (por comparação com durante o exercício), para reabastecimento do glicogénio muscular ${ }^{19}$. Classicamente este tipo de exercício era menos valorizado que o aeróbico na prevenção e tratamento de algumas patologias crónicas, no entanto, estudos mais recentes demonstram que este tem uma eficácia equivalente ou até superior na diminuição do risco cardiometabólico (ou seja, a nível de dislipidemia- níveis das gorduras a circular no sangue, diabetes, hipertensão arterial, composição corporal e marcadores inflamatórios), para além da diminuição do risco de quedas ${ }^{31-33}$ e fraturas, devido à atenuação da osteopenia/ osteoporose (ou seja, 
alteração discreta e intensa da densidade óssea, respetivamente) ${ }^{31,33}$. Muitos investigadores associaram este tipo de exercício a maior sensibilidade insulínica e otimização do controlo da glicemia (segundo alguns trabalhos de forma até mais intensa que para o exercício aeróbico). Contudo, apesar dos benefícios citados, a adesão (sobretudo à medida que a idade avança) é muito baixa; por exemplo, na meia-idade ela é de 10 a $15 \%$, versus $35 \%$ para atividades aeróbicas ${ }^{31}$.

Quando um dos objetivos principais é a perda de peso, deve-se salientar que este tipo de exercício (apesar de não gastar tantas calorias quanto o exercício aeróbico) faz com que se perca massa gorda, mantendo ou até aumentando o gasto calórico em repouso devido a maior massa muscular, potenciando assim a manutenção do ritmo de perda de peso a médio e longo prazos ${ }^{31}$.

Tradicionalmente, este tipo de exercício estava contraindicado nas crianças e jovens, devido ao suposto risco de lesão; contudo, hoje discorda-se; existem outros exercícios praticados e culturalmente aceites para esta fase que representam um impacto ósseo e muscular maior. Para além disso, a síndrome metabólica é cada vez mais prevalente nas crianças $^{34}$.

\section{Como prescrever exercício}

A generalidade da população considera que os profissionais de saúde têm competências técnicas para recomendar, prescrever e acompanhar um plano de exercício ${ }^{26}$. Contudo, ter um médico ou enfermeiro simplesmente a dizer que o indivíduo deveria fazer exercício não é suficiente na maioria dos casos, às vezes mesmo explicando os benefícios gerais que o mesmo traria para patologias já existentes ou muito prováveis de surgirem a curto/ médio prazos. Ainda assim, os profissionais que prestam apoios mais continuados (como nos cuidados primários e na medicina curativa a nível ocupacional) terão maior probabilidade de sucesso 27 .

$\mathrm{Na}$ primeira consulta de prescrição de exercício devem ser colhidos os dados mais relevantes da anamnese e exame físico, podendo requisitar-se exames auxiliares de diagnóstico, variável com as guidelines adotadas, idades e morbilidades. Os objetivos iniciais devem ser realistas (por exemplo, perder 5 a $15 \%$ do peso, se apropriado, em determinado espaço temporal); uma vez atingido o objetivo inicial devem ser estabelecidos outros, e assim sucessivamente ${ }^{19}$.

Qualquer treino deve iniciar-se com uma fase de aquecimento de 5 a 10 minutos (com atividade aeróbica suave) e deve finalizar com alongamentos/ exercícios promotores de flexibilidade, também entre 5 a 10 minutos $^{12}$. Os alongamentos devem ser executados de forma lenta, por exemplo, também ao início e ao final do dia, na horizontal, melhorando a flexibilidade e o risco de quedas nos idosos ${ }^{19}$.

Se cada indivíduo, para além das sessões de exercício, diminuir as atividades sedentárias e aumentar a atividade física diária, tal já implicará um acréscimo significativo do gasto calórico. Alguns exemplos práticos nesse sentido poderão incluir o uso de escadas versus elevador, caminhar em vez de ir de carro ou autocarro, estacionar mais longe, sair 
algumas paragens antes no autocarro, potenciar as atividades domésticas, falar pessoalmente em vez de telefonar ou e-mail, fazer reuniões profissionais a caminhar, passear o próprio cão ou do vizinho, se aplicáveis, por exemplo 8 .

\section{Contextualização à prática clínica}

Os profissionais melhor treinados para a prescrição do exercício são os licenciados em Educação Física; daí que a generalidade dos artigos publicados seja orientada para a elaboração de planos de exercício no local, ou seja, estando o profissional presente para perceber qual é a capacidade física do indivíduo (através da aplicação dos métodos aqui mencionados, não só a nível de aptidão cardiovascular, mas também quantificando a carga máxima para cada exercício de resistência, por exemplo). O médico ou enfermeiro que queira prescrever exercício a partir do seu consultório, sem estar com o indivíduo nesta primeira sessão, não pode obviamente utilizar esta metodologia. Dada a escassez de formação no tema e dada a importância terapêutica e preventiva do exercício em inúmeros contextos de saúde, será muito importante que esses conhecimentos sejam adquiridos através de pesquisas informais ou mesmo, para quem gostar mais do tema, através de formação académica oferecida por diversas faculdades.

-Atividades diversas oferecidas pelos ginásios

O primeiro passo para o prescritor de exercício será praticar ele mesmo algum exercício, adquirindo experiência prática nas modalidades de acesso mais fácil à população, como a musculação de manutenção (pelo menos de forma a conhecer as diversas máquinas e quais as áreas corporais trabalhadas com os diversos exercícios que cada máquina permite) e o cardiofitness (constituído por tapete rolante, máquina simuladora de remo, step, bicicletas diversas/elítica...).

Ir a um ginásio apresenta a desvantagem do indivíduo ter de se deslocar do seu domicílio ou emprego até lá mas, a nível de custo imediato, trata-se da uma das hipóteses mais económicas; o preço está obviamente dependente da zona (mais dispendioso em zonas urbanas) e da sofisticação mas, genericamente, em zonas mais periféricas e económicas pode-se treinar todos os dias por menos que 25 euros mensais. O prescritor deverá sempre alertar que os custos das doenças que o exercício previne/ atenua, ainda que ponderando apenas os critérios económicos (consultas, medicações, outros tratamentos, perda de capacidade de trabalho) são ridiculamente superiores ao que pode ter de pagar para praticar exercício... Aliás, este valor nem deve ser visto como um custo mas como um ótimo investimento num futuro mais saudável e feliz.

A generalidade dos ginásios mais completos oferece um vasto leque de modalidades em aulas com objetivos específicos. Para além disso, algumas empresas poderão criar um ginásio interno ou ter algum protocolo económico com um ginásio local. Por vezes, também é possível organizar aulas específicas nas instalações da empresa (Zumba, Pilates...), sem custo para o funcionário e com uma despesa muito, muito discreta para a empresa.

-Modalidades sem dispêndio económico 
Dado o dispêndio financeiro ser uma das desculpas mais frequentemente usadas para não praticar exercício, o prescritor deverá lembrar que a(s) modalidade(s) escolhida(s) deverá(ão) ser adequadas aos objetivos de saúde e gostos pessoais mas, se o critério financeiro for mais importante, poder-se-á praticar modalidades a custo zero, como caminhar, marchar, correr (na rua, parques ou outras estruturas públicas adequada), além de utilizar equipamentos já adquiridos e/ ou arrumados, como bicicleta normal ou estacionária, tapete rolante, jogos de computador desportivos...).

De relembrar apenas que para algumas das atividades aqui referidas, sobretudo as de maior impacto (como correr) deverá adquirir-se pelo menos umas sapatilhas adequadas a esse efeito; são geralmente mais dispendiosas mas apresentam excelente qualidade, conforto e durabilidade.

O prescritor pode sugerir também ao indivíduo que, caso se aproxime o seu aniversário ou outra data festiva, este poderá pedir aos seus familiares e amigos uma prenda conjunta, relacionada com a inscrição anual em alguma instituição desportiva ou aquisição de material para ter em casa e treinar.

-Jogos de computador

A tecnologia classicamente incentivadora do sedentarismo, também oferece jogos desportivos, permitindo a prática virtual de modalidades exóticas, variadas, ao gosto de cada indivíduo (futebol, basquetebol, boxe, ténis, ping-pong, atletismo, esgrima, skating...) no conforto da casa; esta possibilidade de exercício apresenta as vantagens óbvias de eliminar o tempo e custo de deslocamento até às instalações onde se vai praticar o exercício, executando-o sem qualquer desconforto em alturas do ano mais frias, chuvosas ou quentes e, eventualmente, até a custo zero, quando a tecnologia é oferecida como prenda ou apenas com um dispêndio moderado, quando apenas é necessário adquirir o jogo (uma vez que já se tem a play station em casa, sua ou de um familiar mais novo)... ou então pode o indivíduo "oferecer" ele mesmo a um familiar que goste de jogos de computador e, uma vez que moram todos na mesma casa, poderá também usufruir do presente... Para além disso, poderá ter o prazer de jogar sozinho ou acompanhado e de interromper e retomar o treino sempre que for necessário (auxiliar um familiar numa tarefa, programar uma refeição...).

-Outras modalidades possíveis de praticar no domicílio

Aliás, mantendo as vantagens de fazer exercício em casa, se for do agrado do indivíduo, este poderá adquirir (ou passar a utilizar) um tapete rolante e/ou bicicleta estacionária ou máquina de remo; poderá colocar estes instrumentos em frente a um ecrã e treinar enquanto vê um noticiário, documentário, filme ou série; passa o tempo bem entretido, satisfeito e com muito menor perceção do esforço, dada a distração. Ou, se preferir, poderá estar a ler, mais fácil na bicicleta estacionária, mas também possível no tapete rolante em algumas pessoas, desde que usem uma mão para segurar o livro ou revista e a outra para pousar no braço do tapete, de forma a manter um posicionamento seguro. $O$ custo poderá ser superior às hipóteses anteriores (sobretudo se se considerar adquirir um tapete de boa qualidade), mas é custo único; as bicicletas são geralmente muito mais acessíveis; contudo, mais uma vez, também podem constituir um presente. Se não quiser 
ver televisão ou ler, poderá conversar com a família, desde que estejam todos na mesma divisão (ainda que isso obrigue a uma menor intensidade de exercício). Para além disso, todos estes equipamentos podem ser adquiridos em "segunda mão", praticamente novos (uma vez que grande parte dos indivíduos que os compra pouca ou nada os utiliza), com a eventual orientação em sites especializados, com frequentes publicidades televisivas.

Para quem quiser praticar exercício de resistência e não quiser gastar muito dinheiro ou não tiver espaço para colocar várias máquinas de musculação em casa, poderá simplesmente comprar elásticos TRX (desde que haja um suporte adequado e elevado, no teto ou através de uma árvore com um galho resistente) que permitem uma variedade alucinante de exercícios, usando apenas o peso do próprio corpo (é só pesquisar na internet). Os mais simples poderão custar cerca de $25 \mathrm{E}$, ainda que outros modelos tenham preços muito mais elevados.

\section{-Atividades aquáticas}

Muitos indivíduos apreciam bastante atividades na água. A mais classicamente "prescrita" é a natação (aliás constitui piada entre os profissionais ligados ao desporto o facto de a generalidade dos médicos só saber recomendar a prática de natação a nível de prescrição de exercício); contudo, trata-se de um exercício muito elaborado, cuja prática tecnicamente razoável não está ao alcance da maioria da população, pelo que até poderá não ser a melhor opção- como em qualquer prescrição, deve ser avaliado caso a caso. Outra atividade aquática mais simples é a hidroginástica, preferida sobretudo pela população feminina adulta e idosa. Atividades na água não contribuem para uma melhoria significativa da massa óssea mas, fortalecendo/ aumentando os músculos e trabalhando o equilíbrio, diminui-se o risco de quedas, pelo que, indiretamente, se previnem as fraturas. A nível de custo, dada a criação de inúmeras piscinas municipais em quase todas as zonas do país, o valor é muito mais acessível que praticar o mesmo num clube privado sofisticado.

Outra modalidade é a hidrobyke, que consiste em praticar ciclismo estacionário dentro de uma piscina; é tecnicamente intermédia entre a natação e a hidroginástica, mas já exige alguma robustez e desenvoltura na água.

\section{-Danças}

Existem ainda indivíduos com "paixões" específicas que poderão ser alimentadas, como a dança (de salão, latino-americana, africana ou ritmos mais urbanos e jovens). Nos últimos anos floresceram inúmeras escolas de dança, mas de qualidade variável (às vezes são apenas aulas de ginásio, com o estilo musical adulterado, adicionando uma batida mais forte, para ritmar e permitir aulas tipo "aeróbica"). As escolas mais formais, com professores habilitados, permitem um ensino mais fidedigno mas, geralmente, tornam-se mais dispendiosas (por minuto), porque têm um custo semelhante ao de um ginásio não sofisticado mas, geralmente, apenas existe uma aula semanal de dança (de 60 a 90 minutos). Contudo, entrar neste ambiente motiva o indivíduo e a família a frequentar bares noturnos temáticos, às vezes da própria escola, com excelente ambiente, podendo praticar muito exercício a dançar, mais algumas vezes por semana, com grande diversão (além de treinar em casa alguns passos). 
Por vezes, alguns indivíduos sentem-se inibidos em experimentar estas aulas- a primeira vez (como em qualquer exercício) é gratuita; se se tem par leva-se, se não se tem, não faz diferença... a generalidade das escolas incentiva a troca de par, às vezes, dentro de uma só música, de forma a que se dança igual número de vezes com todos os indivíduos presentes do sexo oposto, incluindo o próprio professor(a) e par, quando aplicável.

Outros ficam inibidos por achar que não têm nenhum jeito: ninguém faz passos de exibição na primeira aula! Todos começam com um pé para a frente, outro para trás ou para o lado; 99\% dos indivíduos tem capacidades motoras de adquirir o ritmo/ técnica corretas; o talento pessoal depois fará com que os passos sejam executados com melhor ou pior apresentação estética ou harmonia, mas praticamente todos os conseguem executar tecnicamente, à medida que as aulas prosseguem.

Contudo, por vezes, é possível realizar mais do que uma aula semanal, uma vez que alguns alunos podem ser convidados a aparecer (sem custo adicional) em aulas equivalentes ou de nível técnico inferior (para auxiliar a progressão dos alunos dessa aula ou se existir um número excessivo de indivíduos do sexo oposto nessa aula).

\section{Exemplos de planos de exercícios}

Nesta secção serão dados exemplos soltos de possibilidades de prescrição que, compostos, consoante os objetivos e gostos do indivíduo, poderão inspirar o plano de exercícios.

Idealmente dever-se-ia praticar exercício todos os dias, mas não é expetável que se passe do sedentarismo para esse patamar, diretamente; aliás, prescrever logo de início um plano que abarcasse todos os dias, seria desmotivador para a maioria (ótima desculpa para nem sequer começar). Contudo, o prescritor deve relembrar que, sobretudo quando um dos objetivos é emagrecer, todos os dias (sem exceção) deve haver maior gasto que aquisição de calorias; se não existir exercício, contando só com o metabolismo basal, para se atingir tal, teria de se comer muito pouco... logo, devemos passar a mensagem humorística que quando se quer emagrecer bastante não precisa de se fazer exercício todos os dias... basta fazer naqueles dias que se planeia comer alguma coisa...

Pensamos que será também relevante avisar os futuros prescritores que quase toda a população se acha incrivelmente ocupada... mesmo os indivíduos que têm empregos dos quais nunca trazem quaisquer tarefas para casa e cujo horário termina a meio da tarde, não assumindo qualquer responsabilidade doméstica ou familiar... Estes, geralmente, são os que têm menor disponibilidade para o exercício... O prescritor deve relembrar que o dia tem 24 horas para todos e que são justamente os indivíduos verdadeiramente ocupados os que têm maior capacidade de adicionar algo às suas tarefas habituais, devido à sua elevada capacidade de organização e coordenação. Para além disso, por melhor ideia que se ache de iniciar a prática de exercício (porque todos the reconhecem benefícios genéricos para a saúde), nunca ninguém terá tempo suficiente para algo que não tem vontade de inserir na sua vida. O que falta a $99 \%$ da população sedentária é motivação e não tempo!

Existem alguns indivíduos que têm uma hora alargada para almoçar; caso lhes agrade a sugestão, poderão utilizar esse tempo para ir praticar algum exercício perto do trabalho e 
realizar uma refeição rápida e saudável no final (trazida de casa, por exemplo) ou também poderão pedir autorização para alargar um pouco mais esse tempo, compensando com uma entrada mais cedo ou saída mais tarde. Outros, por sua vez, poderão reunir condições para treinar antes de ir trabalhar ou preferir treinar logo ao sair do trabalho, nas imediações, regressando a casa mais rapidamente, posteriormente, fora da hora de maior tráfego automóvel.

No Quadro 3 encontram-se recomendações de prescrição para cardiofitness e, no Quadro 4, o mesmo para outras modalidades de fácil acesso e boa aceitação na generalidade da população.

\section{BIBLIOGRAFIA}

1)Mannerkorpi $K$. Dutch fibromyalgia association $20^{\text {th }}$ anniversary manuscripts. $J$ Musculoskel Pain. 2009; 17(3): 287-294.

2)Busch A, Thill P, Barber K, Schachter C, Bidende J, Callacott B. Best practice: e-modelprescribing physical activity and exercise for individuals with fibromyalgia. Physioter Theor Pract. 2008: 24(3), 151-166.

3)Gómez R, Monteiro H, Cossio- Bolaños M, Fama-Cortez D, Zanesco A. El exercicio físico y su prescripción en pacientes com enfermidades crónicas degenerativas. Rev Peru Med Exp Salud Publica. 2010: 27(3), 379-386.

4)Wallace J. Exercise in hypertension- a clinical review. Sport Med. 2003; 33(8): 585-598.

5)Moore S, Rosenthal I. Using guidelines for exercise in cardiac patients. J Am Academy Nurs Practitioners. 2006: 559-565.

6)Farr J, Going S, McKnight P, Kasle S, Cussler E, Cornett M. Progressive resistance training improves overall physical activity levels in patients with early arthritis of the knee: a randomized controlled trial. Physic Ther. 2010; 90(3): 356-366.

7)Cobiac L, Vos T, Barendregt J. Cost-effectiveness of interventions to promote physical activity: a modelling study. PLOS Med. 2009; 6(7): 1-10.

8)Jonas S. Lifestile exercise for the exercise prescription. AMAA J Fall. 2009, 17-22.

9)Hacker E. Exercise and quality of life: strengthening the connections. Clin J Oncol Nurs. 2009; 13(1): 31-37.

10)Brazelli M, Saunders D, Mead G. Physical fitness training for stroke patients. Cochrane Database System Rev. 2011; 11: 1-124.

11)Bragada J, Magalhaes $P$, Vasques $C$, Barbosa T, Lopes $V$. Net heart arte to prescribe physical activity in middle-aged to older active adults. J Sports Sci Med. 2009; 8: 616-621.

12)Alireza $L$, Mohammad $H$, Farzin $H$, Michael $B$. Exercise prescription in patients with diabetes type 2. Iran J Diab Lipid Disord. 2008; 8: 1-15.

13)Warburton D, Nicol C, Bredin S. Prescribing exercise as preventive therapy. CMAJ. 2006; 174(7): 961-974. 
14)Mishra N, Devansho M. Exercise beyond menopause: dos and don'ts. J Mid-Life Health. 2011; 2(2): 51-56.

15)EkkekAkis P, Parfitt G, Petruzello S. The pleasure and displeasure people feel when they exercise at different intensities. Sports Med. 2011; 41(8): 641-671.

16)Castro $M$, Silva $N$, Monteiro $W$, Palma A, Resende $H$. Motivos de permanência dos praticantes nos programas de exercícios físicos oferecidos pelo Serviço Social do Comércio- Brasil. Motricidade. 2010; 6(4): 23-33.

17)Ingram D, Wilbur J, McDevitt J, Buchholz S. Women's walking program for African American women: expectations and recommendations from participants as experts. Womens Health. 2011; 51: 566-582.

18)Jones $F$, Harris $P$, Waller $H$, Coggins $A$. Adherence to an exercise prescription scheme: the role of expectations, self-efficacy, stage of change and psychological wellbeing. British J Health Psychol. 2005; 10: 359-378.

19)Pearse P. Exercise in Medicine. Curr Sports Report. 2008, 171-175.

20)Martin S, Crowover B, Kovac F. What is the best way to motivate patients to exercise? J Fam Pract. 2010; 59(1): 43-45.

21)Stefani L, Maone A, Mascherini G, Scacciati I, Corsani I, Gilardetti A, Ciullini G, Galanti G. Efficacy and educational role of a daily employment of the accelerometer to improve the life style in overweight-hypertensive population. Scires. 2011; 3: 141-145.

22)Colley R, Hills A, O' Moore-Sullivan T, Hickman I, Prins J, Byrne N. Variability in adherence to a supervised exercise prescription in obese women. Int J Obes. 2008; 32: 837-844.

23)Medina-Mirapeix F, Escolar-Reina P, Gascón-Cánovas JJ, Montilla-Herrador J, JimenoSerrano FJ, Collins SM. Predictive value of adherence to frequency and duration components in home exercise programs for neck and low back pain: an observational study. BMC Musculoskel Disord. 2009; 10(155): 1-9.

24)Hills A, Shultz S, Soares M, Byrne N, Hunter G, King N, Misra A. Resistance training for obese, type 2 diabetic adults: a review of the evidence. Obes Revs. 2009; 11: 740-749.

25)Ekkekakis P. Let them roam free? Sports Med. 2009; 39(10): 857-888.

26)Rhodes R, Fiala B. Building motivation and sustainability into the prescription and recommendations for physical activity and exercise therapy: the evidence. Physiol Ther Pract. 2009; 25 (5-6): 424- 441.

27)Weidinger K, Lovegreen S, Elliot M, Hagood L, Haire-Joshu D, McHill J, Browson R. How to make exercise counselling more effective: lessons from rural America. J Fam Pract. 2008; 57(8): 394-400. 
28)Dauenhaver J, Podgorsky C, Karuja J. Prescribing exercise for older adults: a needs assessment comparing primary care physicians, nurse practitioners and physician assistants. Geront Geriat Educat. 2006; 26(3): 81-98.

29)Feehan L, Beck $C$, Harnis $S$, Maclntyre D. Exercise prescription after fragility fracture in older adults: a scoping review. Osteoporos Int. 2011; 22: 1289-1322.

30)Waryasz G, McDermott A. Exercise prescription and the patient with type 2 diabetes: a clinical approach to optimizing patient outcomes. J Am Acad Nurs Pract. 2010; 22: 217227.

31)Philips $S$, Winett $R$. Uncomplicated resistance training and health- related outcomes: evidence for a public health mandate. Am College Sports Med. 2010; 9(4): 208-213.

32)Salles B, Simão R, Miranda F, Novaes J, Lemos A, Willardson J. Rest interval between sets in strength training. Sports Med. 2009; 39(9): 765-777.

33)Bird S, Tarpenning K, Marino F. Designing resistance training programmes to enhance muscular fitness. Sports Med. 2005; 35(10): 841-851.

34)Benson A, Torode E, Singh M. Effects of resistance training on metabolic fitness in children and adolescents: a systematic review. Obes Rev. 2007; 9: 43-66.

35)Lemos M, Valim V, Zandonade E, Natour J. Intensity levels for exercise training in fibromyalgia by using mathematical models. BMC Musculoskel Disord. 2010; 11(54): 1-6.

\section{Quadro 1- Estimativa da intensidade do exercício através da Frequência Cardíaca Máxima (FCM)}

\begin{tabular}{|c|c|c|c|}
\hline & FCT & $(F C M-F C R) X I+F^{2}{ }^{3}$ & $\begin{array}{l}\text { FCT- Frequência cardíaca de treino } \\
\text { FCM- Frequência cardíaca máxima } \\
\text { FCR- Frequência cardíaca em repouso } \\
\text { I-Intensidade }(\%) \\
\text { ID- idade }\end{array}$ \\
\hline \multirow[t]{4}{*}{ FCM } & sexo masculino & 220- ID & \multirow{4}{*}{$\begin{array}{l}\text { FCR- Frequência cardíaca em repouso } \\
\text { I-Intensidade (\%) } \\
\text { ID- idade }\end{array}$} \\
\hline & sexo feminino & 226- ID & \\
\hline & obesos & $220-(0,5 x \text { ID })^{13}$ & \\
\hline & & & \\
\hline
\end{tabular}

\section{Quadro 2- Correlação entre alguns parâmetros com capacidade para estimar a intensidade do exercício}

\begin{tabular}{lllllc}
$\begin{array}{l}\text { Atividade } \\
\text { física }\end{array}$ & $\begin{array}{l}\% \\
\text { FCM }\end{array}$ & $\begin{array}{l}\text { Alterações da frequência } \\
\text { respiratória }\end{array}$ & $\begin{array}{l}\text { \% do consumo de } \\
\text { oxigénio }\end{array}$ & $\begin{array}{l}\text { Alterações na } \\
\text { temperatura }\end{array}$ & $\begin{array}{l}\text { Escala de } \\
\text { Borg }\end{array}$ \\
\hline $\begin{array}{l}\text { Muito } \\
\text { suave }\end{array}$ & $<35$ & Sem & $<20$ & Sem & 110 \\
\hline Suave & $\begin{array}{l}35- \\
54\end{array}$ & Aumento muito discreto & $20-39$ & $\begin{array}{l}\text { Começa a } \\
\text { aumentar }\end{array}$ & $10-11$ \\
\hline Moderada & $55-$ & Aumento discreto & $40-59$ & Quente & $12-13$ \\
& 69 & & & Muito quente & $14-16$
\end{tabular}




\begin{tabular}{lllccc}
\hline $\begin{array}{l}\text { Muito } \\
\text { intensa }\end{array}$ & $\begin{array}{l}90- \\
99\end{array}$ & Aumento intenso & $85-99$ & Muitíssimo quente & $17-29$ \\
\hline Máxima & 100 & Aumento máximo & 100 & Sudorese máxima & $20^{12,13}$ \\
\hline
\end{tabular}

\section{Quadro 3-Exemplo de um plano de Cardifitness}

\begin{tabular}{|c|c|c|c|c|c|}
\hline \multicolumn{2}{|c|}{ CARDIOFITNESS } & \multirow{2}{*}{$\begin{array}{l}\text { Tempo } \\
\text { inicial } \\
\text { (min) } \\
5\end{array}$} & \multirow{2}{*}{$\begin{array}{l}\text { Intensidade } \\
(\mathrm{km} / \mathrm{h})\end{array}$} & \multirow{2}{*}{$\begin{array}{l}\text { Tempo } \\
\text { máximo } \\
(\min )\end{array}$} & \multirow{2}{*}{$\begin{array}{l}\text { Progressão } \\
\begin{array}{l}\uparrow 0,1 \mathrm{~km} / \mathrm{h} \text { por semana, até o máx de } 6 \\
\mathrm{~km} / \mathrm{h}\end{array}\end{array}$} \\
\hline $\begin{array}{l}\text { Tapete } \\
\text { rolante }\end{array}$ & Aquecimento & & & & \\
\hline & Corrida & 1 & 6,5 & 15 & $\begin{array}{l}\uparrow 1 \text { min por mês, até } 15 \mathrm{~min} \text {; depois } \\
\text { aumentar } 0,1 \mathrm{~km} / \mathrm{h} \text { por semana }\end{array}$ \\
\hline & Subida & 20 & $\begin{array}{l}5 \mathrm{~km} / \mathrm{h} \text { com } \\
\text { menor } \\
\text { inclinação }\end{array}$ & $\begin{array}{l}\text { Sempre } \\
20\end{array}$ & $\begin{array}{l}\uparrow \text { um patamar de inclinação por mês; qt } \\
\text { estiver com inclinação máxima, aumentar } \\
0,1 \mathrm{~km} / \mathrm{h} \text { por semana, até o máximo de } 6,5 \\
\mathrm{~km} / \mathrm{h}\end{array}$ \\
\hline & Finalização & 5 & 4 & $\begin{array}{l}\text { Sempre } \\
5\end{array}$ & $\begin{array}{l}\uparrow 0,1 \mathrm{~km} / \mathrm{h} \text { por semana, até o máximo de } 6 \\
\mathrm{~km} / \mathrm{h}\end{array}$ \\
\hline Remo & & 5 & $\begin{array}{l}\text { Não se } \\
\text { aplica }\end{array}$ & 15 & $\uparrow 1$ min por semana \\
\hline Elíptica & & 5 & $\begin{array}{l}\text { Grau } 1 \text { de } \\
\text { intensidade }\end{array}$ & 15 & $\begin{array}{l}\uparrow 1 \text { min por semana, até o máx de } 15 \text { min, } \\
\text { aí aumentar } 1 \text { grau de intensidade por mês }\end{array}$ \\
\hline \multicolumn{2}{|c|}{$\begin{array}{l}\text { Bicicleta } \\
\text { (pernas na horizontal) }\end{array}$} & 10 & $\begin{array}{l}\text { Sem atrito, } \\
\text { menor } \\
\text { intensidade }\end{array}$ & $\begin{array}{l}\text { Sempre } \\
10\end{array}$ & Sem evolução \\
\hline \multicolumn{2}{|c|}{$\begin{array}{l}\text { Bicicleta } \\
\text { (pernas na vertical- } \\
\text { "normal") }\end{array}$} & 10 & $\begin{array}{l}\text { Sem atrito, } \\
\text { menor } \\
\text { intensidade }\end{array}$ & $\begin{array}{l}\text { Sempre } \\
10\end{array}$ & Sem evolução \\
\hline
\end{tabular}

\section{Quadro 4- Exemplos soltos de planos de prescrição de diversas modalidades}

Plano de prescrição

Musculação (pedir descrição das máquinas disponíveis- todos os ginásios têm uma folha com as mesmas, para o monitor elaborar o plano de exercício dos clientes)

Genericamente realizar 3 séries de 8 a 15 repetições, a 50 a $85 \%$ da carga máxima, com 1 a 5 minutos de intervalo entre as séries, 1 a 3 dias por semana

Aulas de Treinar o maior número de dias possíveis de aulas pagas/ oferecidas e efetuar o dança maior número de saídas noturnas e treinos no domicílio

Caminhada Treinos com um mínimo de 60 minutos: repetir pelo menos 6 vezes a sequência de 9 de rua minutos a caminhar com 1 minuto a correr; sem parar; por cada semana tirar 1 minuto à caminhada e dar à corrida (8/2, 7/3, 6/4 e assim, sucessivamente). Tentar também, simultaneamente, aumentar a velocidade da caminhada. Após 10 semanas (quando estiver a correr 60 minutos seguidos), poderá aumentar 5 minutos de corrida por mês. Relembrar o indivíduo que poderá ajustar a velocidade da corrida às suas características e fazê-la de forma mais suave nos primeiros meses

Natação

Hidroginástica
Realizar o maior número de treinos semanais possíveis, seguindo as orientações do professor 
(1) Santos M.: Licenciada em Medicina; Especialista em Medicina Geral e Familiar; Mestre em Ciências do Desporto; Especialista em Medicina do Trabalho; Presentemente a exercer nas empresas Medicisforma, Clinae, Servinecra e Serviço Intermédico; Diretora Clínica da empresa Quercia; Diretora da Revista Portuguesa de Saúde Ocupacional on line

(2) Almeida A:. Mestre em Enfermagem Avançada; Especialista em Enfermagem Comunitária; Pós-graduado em Supervisão Clínica e em Sistemas de Informação em Enfermagem; Docente na Escola de Enfermagem (Porto), Instituto da Ciências da Saúde da Universidade Católica Portuguesa; Diretor Adjunto da Revista Portuguesa de Saúde Ocupacional on line

Santos M, Almeida A. Como prescrever exercício em contexto laboral? Revista Portuguesa de Saúde Ocupacional on line. 2016, volume 1, 1-10. 